\title{
Lithium Bis(oxalate)borate as an Electrolyte Salt for Supercapacitors in Elevated Temperature Applications
}

\author{
Alfred Madzvamuse, Louis Hamenu, Latifatu Mohammed, Chris Yeajoon Bon, Sang Jun Kim, \\ Jeong Ho Park, and Jang Myoun Ko* \\ Department of Chemical and Biological Engineering, Hanbat National University, Daejeon 34158, Republic of Korea
}

\begin{abstract}
The electrolyte plays one of the most significant roles in the performance of electrochemical supercapacitors. Most liquid organic electrolytes used commercially have temperature and potential range constraints, which limit the possible energy and power output of the supercapacitor. The effect of elevated temperature on a lithium bis(oxalate)borate(LiBOB) saltbased electrolyte was evaluated in a symmetric supercapacitor assembled with activated carbon electrodes and different electrolyte blends of acetonitrile( $\mathrm{ACN})$ and propylene carbonate( $\mathrm{PC})$. The electrochemical properties were investigated using linear sweep voltammetry, cyclic voltammetry, galvanostatic charge-discharge cycles, and electrochemical impedance spectroscopy. In particular, it was shown that $\mathrm{LiBOB}$ is stable at an operational temperature of $80^{\circ} \mathrm{C}$, and that, blending the solvents helps to improve the overall performance of the supercapacitor. The cells retained about $81 \%$ of the initial specific capacitance after 1000 galvanic cycles in the potential range of $0-2.5 \mathrm{~V}$. Thus, LiBOB/ACN:PC electrolytes exhibit a promising role in supercapacitor applications under elevated temperature conditions.
\end{abstract}

Keywords : Elevated temperature, Lithium bis(oxalate)borate, Supercapacitor

Received : 20 July 2017, Accepted : 8 November 2017

\section{Introduction}

Supercapacitors are an attractive power source in various fields of application, such as automotive and electric vehicles, aerospace equipment, military, memory devices, and other simple electronic devices. In many of these fields, the need for high power and energy density is paramount for the supercapacitor despite the harsh temperature environments associated with these applications [1-3]. Although the electrode material plays a role in determining the energy density of a cell, the electrolyte has a crucial role since it is directly in contact with all the important components of a cell. Also, temperature has a profound effect on electrolyte kinetics and the rate capability of a cell [4]. An electrolyte is composed of a salt and a solvent with high dielectric property [5],

*E-mail address: jmko@hanbat.ac.kr

DOI: https://doi.org/10.5229/JECST.2017.8.4.314 and is required to possess certain characteristics to ensure optimum operation within a cell: (i) high ionic conductivity to ease ion transfer between electrodes and no electronic conductivity to avert self-discharge and short-circuiting [6-8]; (ii) a wide potential window, in which the electrolyte and electrodes are stable [9]; (iii) non-flammability, along with low vapor pressure, to circumvent fire in the event of failure [10]; (iv) thermal and chemical stability [11]; (v) low cost; and (vi) low toxicity.

Most commercial supercapacitors available in the market employ liquid organic electrolytes due to their moderately high ionic conductivity (about $10^{-2} \mathrm{Scm}^{-1}$ ) [12], high voltage of up to $2.8 \mathrm{~V}$ (in acetonitrile(ACN) medium) [13], and good thermal stability in the temperature range of -40 to $70^{\circ} \mathrm{C}[14]$. Even for common organic electrolytes such as ACN or propylene carbonate (PC) solvent with quaternary ammonium salts, similar operational restrictions are encountered at elevated temperatures, as in batteries. 
Tetraalkylammonium salts have been utilized over the years because of their good solubility in nonaqueous solvents and reasonably good conductivity. These are, however, costly and susceptible to hydrolysis when exposed to moisture, and subsequent recombination shuttle reactions lead to self-discharge [15]. Lithium bis(oxalato)borate(LiBOB) is stable at high temperatures $[16,17]$ when used in organic solvents such as ethylene carbonate(EC), diethyl carbonate(DEC), and PC, as well as their varied mixtures, for lithium ion battery(LIB) applications. In addition, organic electrolytes exhibit wide potential windows greater than $4.5 \mathrm{~V}$ [18], which deliver high energy during operation [19].

This paper first presents LiBOB salt in $\mathrm{ACN}$ and $\mathrm{PC}$ organic solvents as electrolytes for supercapacitor applications at an elevated temperature of $80^{\circ} \mathrm{C}$. Combinations of the two solvents(ACN and $\mathrm{PC}$ ) are then characterized by cyclic voltammetry, linear sweep voltammetry, electrochemical impedance spectroscopy, and galvanostatic charge-discharge. Next, the morphological properties of the electrode are studied using SEM, based on which some conclusions are made.

\section{Experimental}

Activated carbon electrodes were prepared from a viscous slurry in the following composition: activated carbon(MSC-30, Kansai Cokes), poly(vinylidene fluoride)(Aldrich) as a binder, and vapor-grown carbon fiber(Showa Denko) with a weight ratio of $8: 1: 1$ (w/ w), respectively. The N-methyl-2-pyrrolidone (Aldrich) solvent served as the dispersion medium. The slurry was cast on an aluminum foil current collector( $15 \mu \mathrm{m}$ thick) with a doctor blade apparatus and dried at $120^{\circ} \mathrm{C}$ to evaporate the solvent. Circular sheets of electrodes with a diameter of $16 \mathrm{~mm}$ were then cut and further dried at $60^{\circ} \mathrm{C}$ in a vacuum oven for $24 \mathrm{~h}$. The loading density of the electrodes was about $4.73 \mathrm{mgcm}^{-2}$.

ACN, PC, and LiBOB (Aldrich 99\%) were used to prepare various electrolyte systems of $0.9 \mathrm{M}$ concentration with respect to the LiBOB salt in an argonfilled glove box. The ACN:PC electrolyte ratio mixtures were as follows: $1: 0,4: 1,5: 1$, and $0: 1(\mathrm{v} / \mathrm{v})$. The ionic conductivity values of the electrolytes were determined using a conductivity cell consisting of stainless steel electrodes. The conductivity values were then calculated from the impedance measurements performed at $80^{\circ} \mathrm{C}$ using equation 1 :

$$
C=\frac{l}{A R}
$$

where $C, l, A$, and $R$ represent the ionic conductivity $\left(\mathrm{mScm}^{-1}\right)$, separation of electrodes $(\mathrm{cm})$, area of electrodes $\left(\mathrm{cm}^{2}\right)$, and solution resistance $(\mathrm{m} \Omega)$ taken from the Nyquist plot, respectively.

This was followed by a cell assembly of CR 2032 stainless-steel coin cells, which consisted of two identical activated carbon electrodes separated by a $\mathrm{SiC}$ mat separator and the as-prepared electrolytes.

The cells were characterized at a temperature of $80^{\circ} \mathrm{C}$ by cyclic voltammetry using an Autolab instrument (PGstat 100, Eco Chemie). The potential ranges of $0-2.5$ and $0-2.8 \mathrm{~V}$ at various scan rates ranging from 20 to $300 \mathrm{mVs}^{-1}$ were used. Linear sweep voltammetry analysis was conducted on stainless-steel electrodes separated by a $\mathrm{SiC}$ mat separator at a scan rate of $10 \mathrm{mVs}^{-1}$. Galvanostatic charge-discharge was also carried out at a current density of $5 \mathrm{mAcm}^{-2}$ over the potential ranges of $0-2.5$ and $0-2.8 \mathrm{~V}$. The cycle life test was conducted at the same temperature and comprised 1000 cycles taken at a $200 \mathrm{mVs}^{-1}$ scan rate over potential ranges of 0-2.5 and 0-2.8 V. The specific capacitance $\left(C_{\mathrm{sp}}\right)$ was determined as a function of scan rate using equation 2 :

$$
C_{s p}=\frac{q_{a}+q_{c}}{2 \cdot m \cdot \Delta V}
$$

where $q_{\mathrm{a}}$ and $q_{\mathrm{c}}$ indicate anodic and cathodic charges on each scan, $m$ denotes mass of the active material, and $\Delta V$ represents the potential window of the cyclic voltammogram. The specific energy $E\left(\mathrm{Whkg}^{-1}\right)$, also called energy density, in a supercapacitor is given by equation 3:

$$
E=\frac{C \cdot U^{2}}{2 \cdot m \cdot 3600}
$$

where $C$ is the capacitance, $U$ is the potential range, and $m$ is the mass of the active material. The maximum specific power $\left(\mathrm{Wkg}^{-1}\right)$ is determined by equation 4:

$$
P=\frac{U^{2}}{4 \cdot E S R \cdot m}
$$

where ESR stands for the equivalent series resistance $(\Omega)$. Complex impedance measurement was 
also performed on the cells at $80^{\circ} \mathrm{C}$ using a frequency response analyzer in the frequency range of $10^{-2}$ $10^{6} \mathrm{~Hz}$ to study the interfacial properties before and after the electrochemical analysis. The SEM morphological analysis was conducted using a HITACHI S4800 instrument.

\section{Results and Discussion}

\subsection{Electrolyte analysis}

The stability of the electrolyte systems was determined to establish the anodic oxidation potential of the electrolyte as shown in . Over the set potential range of 0-3 $\mathrm{V}, \mathrm{LiBOB} / \mathrm{PC}$ was found to be the most stable, while $\mathrm{LiBOB} / \mathrm{ACN}$ was the least stable. The theoretical electrochemical stability window is determined from the gap between the highest occupied molecular orbital and lowest unoccupied molecular orbital of the electrolyte system, which is based on

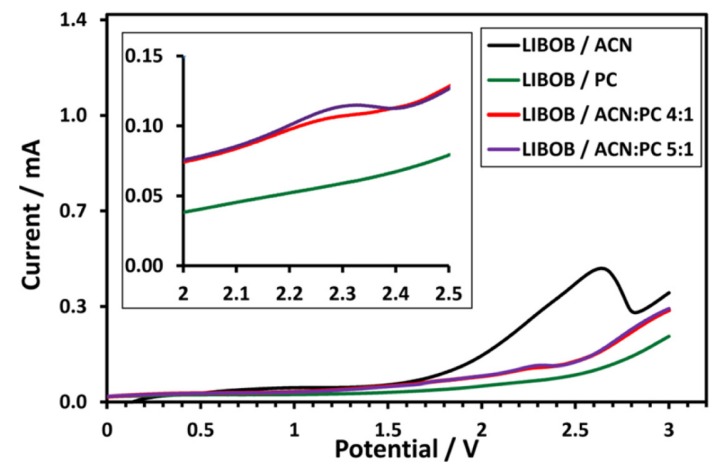

Fig. 1. Linear sweep voltammogram for the electrolytes taken at a scan rate of $10 \mathrm{mVs}^{-1}$.
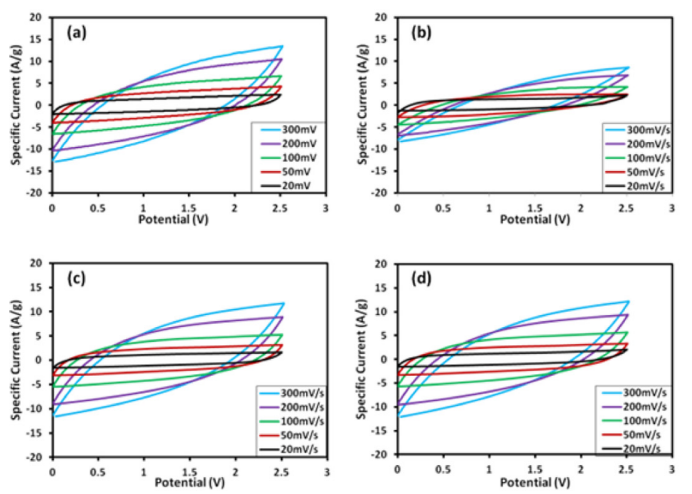

the chemistry of both the solvent and salt [20]. The solvent of each electrolyte system plays an important role in the potential range that can be attained by the supercapacitor during operation. $\mathrm{LiBOB} / \mathrm{PC}$ is the most desirable since it withstands oxidation very well with an increase in the applied potential. LiBOB/ $\mathrm{ACN}$, on the other hand, succumbed to produce an oxidation peak that was lower than the $2.8 \mathrm{~V}$ limit reported at room temperature [13]. LiBOB/ACN's shift to a lower oxidation potential resulted from a narrower electrochemical window of stability [5], which was made more vulnerable at elevated temperatures. The inset in shows how PC properties suppressed the oxidation in the LiBOB/ACN:PC 5:1 and 4:1 blends. A smaller volume ratio of the PC component in the LiBOB/ACN:PC 5:1 blend reduced the electrolyte oxidation. However, a further increase in $\mathrm{PC}$ to the mixture, as seen in the LiBOB/ACN:PC $4: 1$ blend, rendered complete suppression of the oxidation peak.

The anion of the salt is also very important as it determines the upper potential limit for the electrolyte $[21,22]$. The $\mathrm{BOB}^{-}$anion has been shown to be stable against platinum electrodes up to about $4.5 \mathrm{~V}$ [23]. Thus, the observed oxidation most likely results from the oxidation of the solvent rather than that of the $\mathrm{BOB}^{-}$anion. The blended electrolytes, $\mathrm{LiBOB} /$ ACN:PC 4:1 and LiBOB/ACN:PC 5:1, exhibited better stability than pristine $\mathrm{LiBOB} / \mathrm{ACN}$ and had profiles that were almost identical. This testified to the stabilizing effect obtained from the addition of the PC component to the LiBOB/ACN electrolyte system under these stringent conditions. The ionic conductivities of the electrolytes, as calculated from equation 1 ,
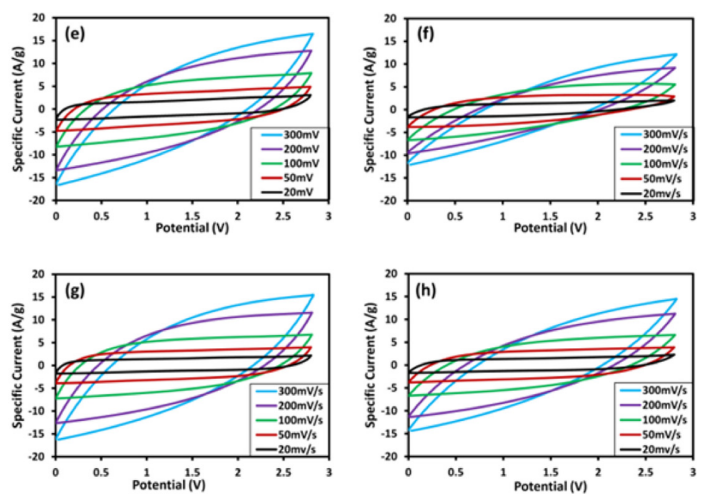

Fig. 2. Cyclic voltammograms for electrolytes LiBOB/ACN, LiBOB/PC, LiBOB/ACN:PC 4:1, and LiBOB/ACN:PC 5:1 over $2.5 \mathrm{~V}(\mathrm{a}, \mathrm{b}, \mathrm{c}$, and $\mathrm{d})$ and $2.8 \mathrm{~V}(\mathrm{e}, \mathrm{f}, \mathrm{g}$, and $\mathrm{h}$, respectively) potential ranges. 
were $29.52,15.39,24.31$, and $26.75 \mathrm{mScm}^{-1}$ for $\mathrm{LiBOB} / \mathrm{ACN}, \mathrm{LiBOB} / \mathrm{PC}, \mathrm{LiBOB} / \mathrm{ACN}: \mathrm{PC} 4: 1$, and $\mathrm{LiBOB} / \mathrm{ACN}: \mathrm{PC} 5: 1$, respectively. These values were also obtained at $80^{\circ} \mathrm{C}$. The pristine $\mathrm{LiBOB} /$ $\mathrm{ACN}$ exhibited the largest ionic conductivity, while LiBOB/PC exhibited the least. The blended electrolytes, LiBOB/ACN:PC 4:1 and 5:1, showed ion conductivity values that were in between those of the two pristine electrolytes. These values showed good ionic conductivity properties of the electrolytes.

\subsection{Cell analysis}

The cyclic voltammetry analysis in Fig. 2 shows the behavior of individual electrolytes in the two potential ranges. The uniformly scaled voltammograms are also shown at various scan rates. All the electrolytes produced profiles that had good symmetry, which alludes to the reversibility of the chargingdischarging process. Also, the blended electrolytes displayed specific capacitances comparable to those of pristine $\mathrm{LiBOB} / \mathrm{ACN}$, while $\mathrm{LiBOB} / \mathrm{PC}$ exhibited the smallest specific capacitance (Fig. 3). This was because of the low ionic mobility [24] of the LiBOB/ PC electrolyte due to solvent viscosity. As a result, the formation of the electric double layer in the PC electrolyte was much slower than that of the other electrolytes.

Fig. 3 (a) and (b) show the different electrolyte systems at various scan rates and potential ranges of 0 2.5 and $0-2.8 \mathrm{~V}$, respectively. The relation shows that as scan rate increases, specific capacitance decreases. This general trend was seen for all electrolytes at both potential ranges. At a potential range of $0-2.5 \mathrm{~V}$, the calculated specific capacitances were $34.7,30.4$, 29.4, and $28.1 \mathrm{Fg}^{-1}$, corresponding to $\mathrm{LiBOB} / \mathrm{ACN}$, LiBOB/ACN:PC 5:1, LiBOB/ACN:PC 4:1, and $\mathrm{LiBOB} / \mathrm{PC}$, respectively, at a $20 \mathrm{mVs}^{-1}$ scan rate. This was consistent with the earlier results observed for cyclic voltammetry and was due to the ion mobility differences of the electrolytes [11]. That is, the lower ion mobility of LiBOB/PC limited the overall specific capacitance as the scan rate of the cell was increased. At a potential range of $0-2.8 \mathrm{~V}$, the specific capacitances obtained were $41.3,33.4,32.4$, and $30.6 \mathrm{Fg}^{-1}$, corresponding to $\mathrm{LiBOB} / \mathrm{ACN}, \mathrm{LiBOB} /$ ACN:PC 5:1, LiBOB/ACN:PC 4:1, and LiBOB/PC, respectively, again at a $20 \mathrm{mVs}^{-1}$ scan rate. (c) shows that the blended electrolytes produced more rectangular and symmetric cyclic voltammograms, which indicates better reversibility during cycling. The area
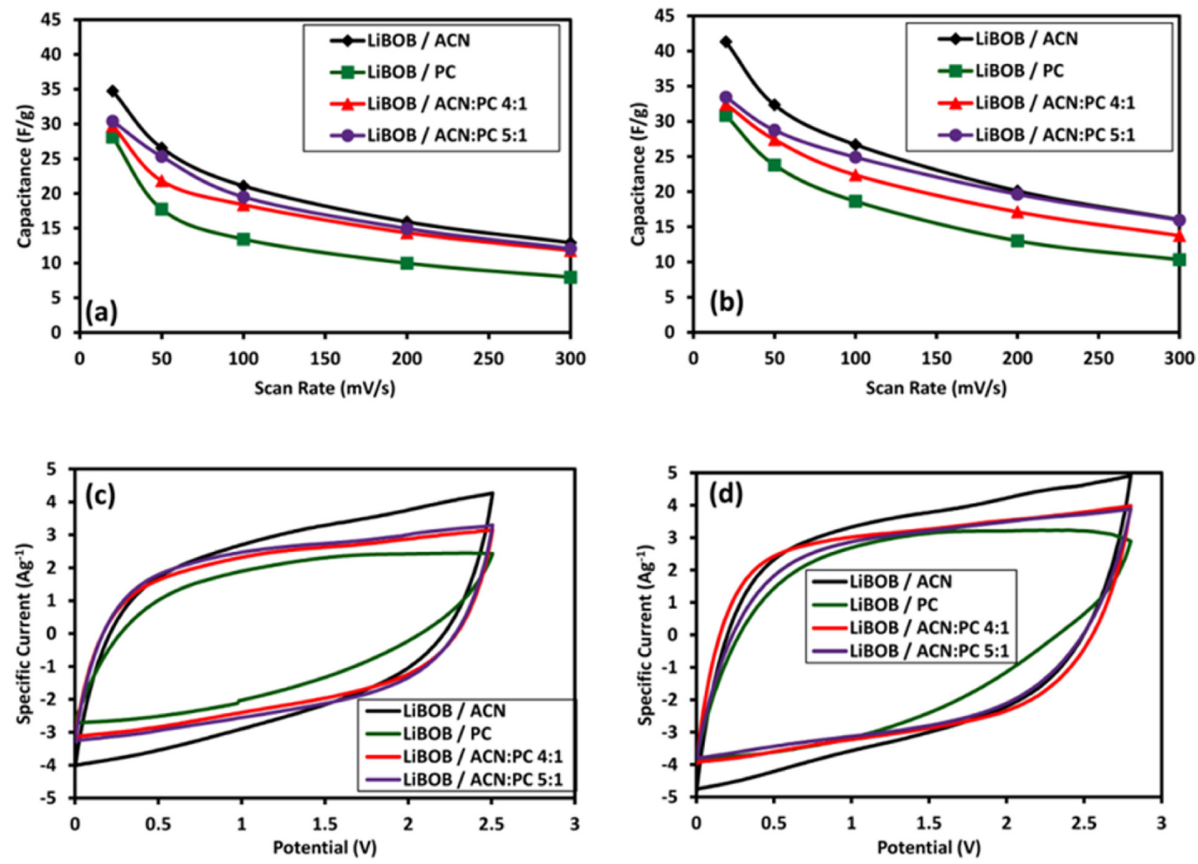

Fig. 3. Profiles of the specific capacitance of the electrolytes as a function of scan rate at $2.5 \mathrm{~V}$ (a) and $2.8 \mathrm{~V}$ (b) and cyclic voltammograms measured at $50 \mathrm{mVs}^{-1}$ with a potential range of (c) $0-2.5 \mathrm{~V}$ and (d) $0-2.8 \mathrm{~V}$. 

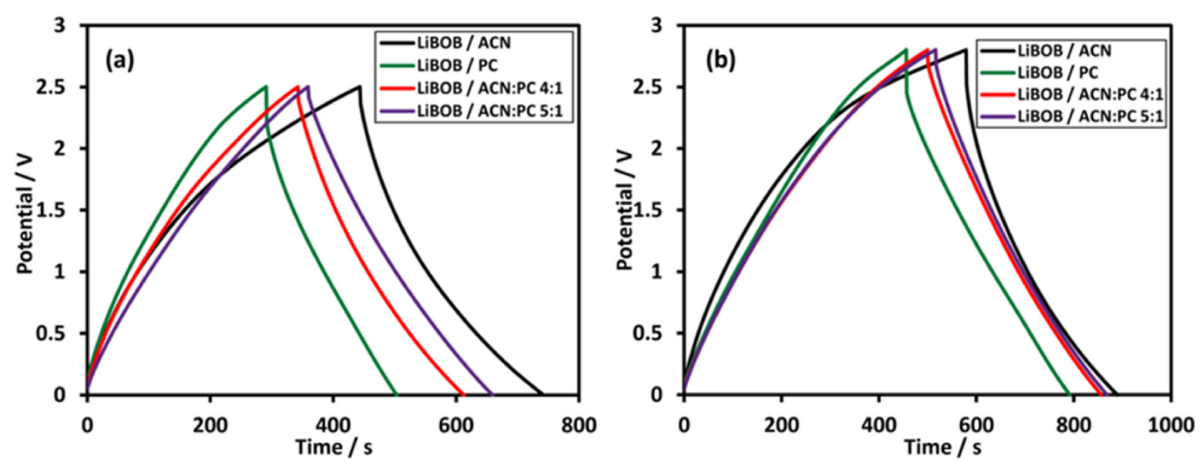

Fig. 4. Galvanostatic charge-discharge profiles for the electrolytes at (a) $2.5 \mathrm{~V}$ and (b) $2.8 \mathrm{~V}$ potential ranges with current density of $5 \mathrm{mAcm}^{-2}$.

of each profile also shows that the blended electrolytes had a specific capacitance lying between those of $\mathrm{LiBOB} / \mathrm{ACN}$ and $\mathrm{LiBOB} / \mathrm{PC}$. (d) compares the voltammograms at $50 \mathrm{mVs}^{-1}$ with the voltage range extended to $2.8 \mathrm{~V}$.

The LiBOB/ACN electrolyte system had the longest charge-discharge time, indicating that it realized the largest capacitance while the least time was exhibited by LiBOB/PC. The blended electrolytes, however, gave times that were intermediary between $\mathrm{LiBOB} / \mathrm{ACN}$ and LiBOB/PC, as shown in Fig. 4 (a) and (b). The charge-discharge profiles show that the charge profile was not linear and much longer than the discharge profile indicating that irreversible faradaic reactions during charge. This poor coulombic efficiency was an indication of the negative effect of high temperature, which leads to poor stability in typical cells. The magnitude of the IR drop during charge-discharge from the minimum to the maximum was in the order LiBOB/ACN:PC 5:1, LiBOB/ ACN:PC 4:1, pristine LiBOB/ACN, and finally, $\mathrm{LiBOB} / \mathrm{PC}$. IR drop is associated with the ESR of the cell and is a cumulative total of all factors that contribute to the resistance. One of the factors is the viscosity of the solvent. Highly viscous solvents inhibit ion migration to and from the electrodes during the charging-discharging process. $\mathrm{ACN}$, for that matter, is less viscous than PC [25], which was reflected in the ionic conductivities of the electrolytes determined earlier. The blended electrolytes and pristine LiBOB/ ACN exhibited better ion mobility, as observed by the smaller IR drop when compared to pristine $\mathrm{LiBOB} / \mathrm{PC}$ at $2.5 \mathrm{~V}$. At $2.8 \mathrm{~V}$, however, the IR drop for $\mathrm{LiBOB} / \mathrm{ACN}$ increased significantly due to elec- trolyte decomposition, as observed by the linear sweep voltammetry analysis in Fig. 1. This trend was less prominent in the blends due to the stabilizing effect of the PC component of the electrolyte system.

The results from the electrochemical impedance spectroscopy characterization are shown in Fig. 5. The impedance measurements were taken after five cycles and then again after 1000 cycles for the two operating potentials of 2.5 and $2.8 \mathrm{~V}$. The Nyquist plots were characterized by a semicircle in the highto-medium frequency region and a tail in the low-frequency region. A semicircle represents the presence of an interphase charge-transfer resistance [26]. This resistance increased slightly with cycling, which implied that the electrode stability was good and affirmed the desired electrolyte compatibility with the electrode. A look at the low-frequency region of the Nyquist plot indicates that little resistance was offered to the electrolyte ionic diffusion into the porous network of the electrodes [27]. At $2.5 \mathrm{~V}$ before cycling, ACN had the lowest solution resistance of $2.6 \Omega$, followed by LiBOB/ACN:PC 5:1 $(3.1 \Omega)$, then LiBOB/ACN:PC $4: 1$ (5.3 $\Omega$ ), and finally, $\mathrm{LiBOB} / \mathrm{PC}$ with $6.3 \Omega$ as shown in (a) and $5(\mathrm{c})$. The solution resistance value increased significantly after 1000 cycles for all electrolytes. Interestingly, the electrolyte blends LiBOB/ACN:PC (4:1 and 5:1) showed the least variation in solution resistance relative to the pure $\mathrm{LiBOB} / \mathrm{ACN}$ and $\mathrm{LiBOB} /$ PC. LiBOB/ACN:PC 4:1, in particular, recorded 5.3 and $5.4 \Omega$ solution resistance before and after cycling, respectively. The Nyquist plots for the cells in the $2.8 \mathrm{~V}$ potential range exhibited characteristics similar to those at $2.5 \mathrm{~V}$. Again, $\mathrm{LiBOB} / \mathrm{ACN}$ 

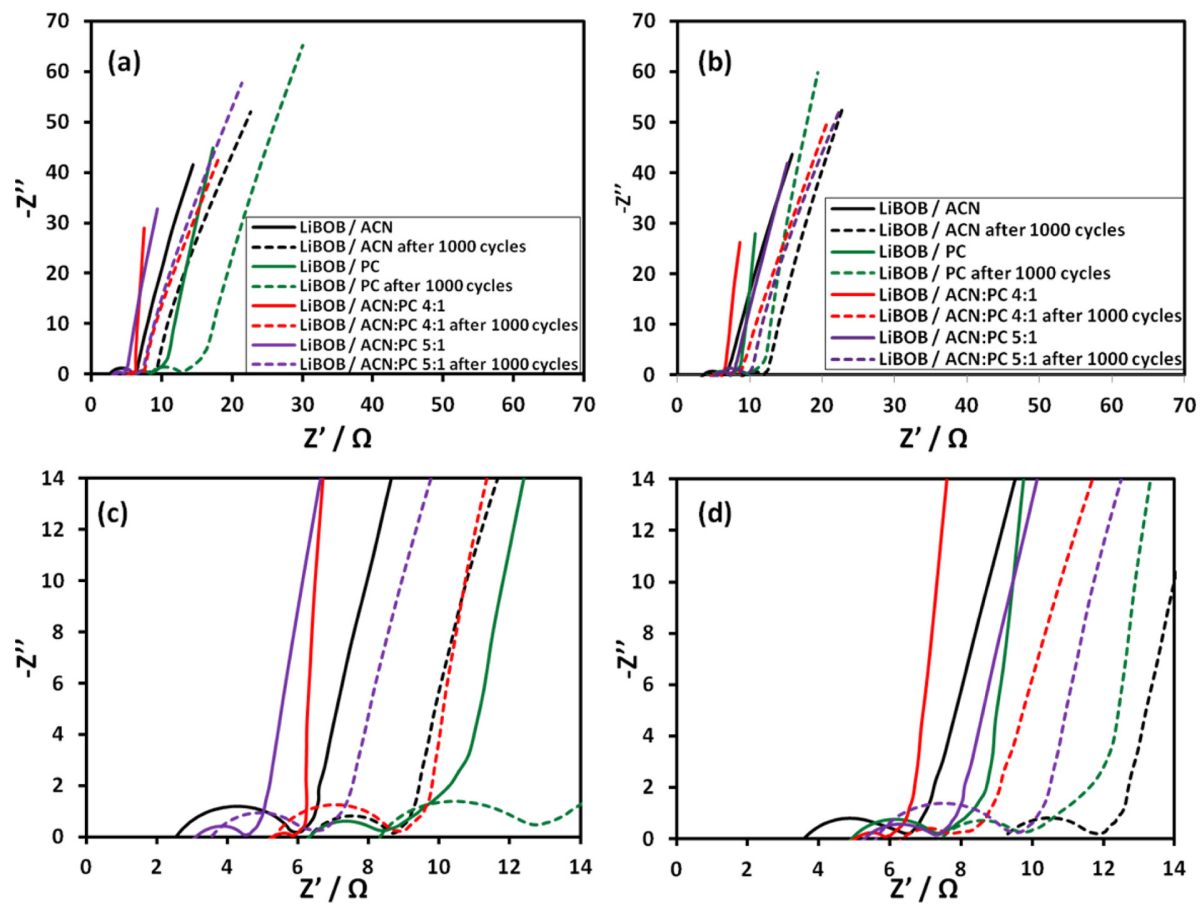

Fig. 5. Nyquist plots for the electrolytes before and after cycling at $2.5 \mathrm{~V}(\mathrm{a}$ and $\mathrm{c})$ and $2.8 \mathrm{~V}(\mathrm{~b}$ and $\mathrm{d})$ potential ranges.

recorded the lowest solution resistance of $3.6 \Omega$ after initial cycling, while LiBOB/PC, and LiBOB/ ACN:PC 4:1 and 5:1 showed comparable values of $4.9,5.0$, and $5.3 \Omega$, respectively, as seen in Fig. 5 (b) and (d). The low solution resistance observed in $\mathrm{LiBOB} / \mathrm{ACN}$ was attributed to the low-viscosity solvent component of the electrolyte. However, LiBOB/ $\mathrm{ACN}$ again displayed the largest gain in solution resistance of about $5.6 \Omega$ at a $2.8 \mathrm{~V}$ potential range. This resistance build-up was consistent with the rapid loss in capacitance observed in Fig. 6 when compared to the other electrolytes.

The cycling stability profiles of the different electrolyte systems in Fig. 6 show that there was a general loss in capacitance with an increase in cycle number for all electrolytes. This decline was attributed to the harsh conditions of an elevated temperature in conjunction with an increase in the solution resistance of the cells due to electrolyte oxidation. $\mathrm{LiBOB} / \mathrm{ACN}$ had the largest initial loss in capacitance after 100 cycles for both potential ranges. That is, about $59.4 \%$ and $68.2 \%$ of the specific capacitance was retained at $2.5 \mathrm{~V}$ and $2.8 \mathrm{~V}$, respectively, as shown in Fig. 6 (a) and (b). Thereafter, the rate of decline decreased gently and stabilized toward the end. The proximity of the set temperature to the boiling point of the ACN solvent (about $82 \mathrm{C}$ ) was the likely reason. When the operation temperature was near or above the solvent boiling point, it began to evaporate, which resulted in an increase in the internal cell pressure. This was consistent with the Arrhenius model which elucidates the accelerated aging process at elevated temperatures [28]. also shows that the addition of $\mathrm{PC}$ to $\mathrm{LiBOB} / \mathrm{ACN}$ improved the stability by almost $74 \%$ over the $0-2.5 \mathrm{~V}$ range and by $45 \%$ over the $0-2.8 \mathrm{~V}$ range for the $\mathrm{LiBOB} / \mathrm{ACN}: \mathrm{PC}$ $4: 1$ blend after 1000 cycles, which were the maximum recorded values.

The LiBOB/ACN:PC 5:1 mixture produced a specific capacitance value comparable to that of $\mathrm{LiBOB} /$ $\mathrm{PC}$ after 1000 cycles, and was $35 \%$ more than that of $\mathrm{LiBOB} / \mathrm{ACN}$ in the $2.5 \mathrm{~V}$ range. This increase was also consistent since it yielded about $40 \%$ more over the $2.8 \mathrm{~V}$ range after 1000 cycles. The stability of $\mathrm{LiBOB} / \mathrm{PC}$ was also exhibited at both potential ranges(Fig. 6), given that it maintained over $80 \%$ of the initial capacitance in the first 100 cycles and followed through to 1000 cycles with over $92 \%$ reten- 

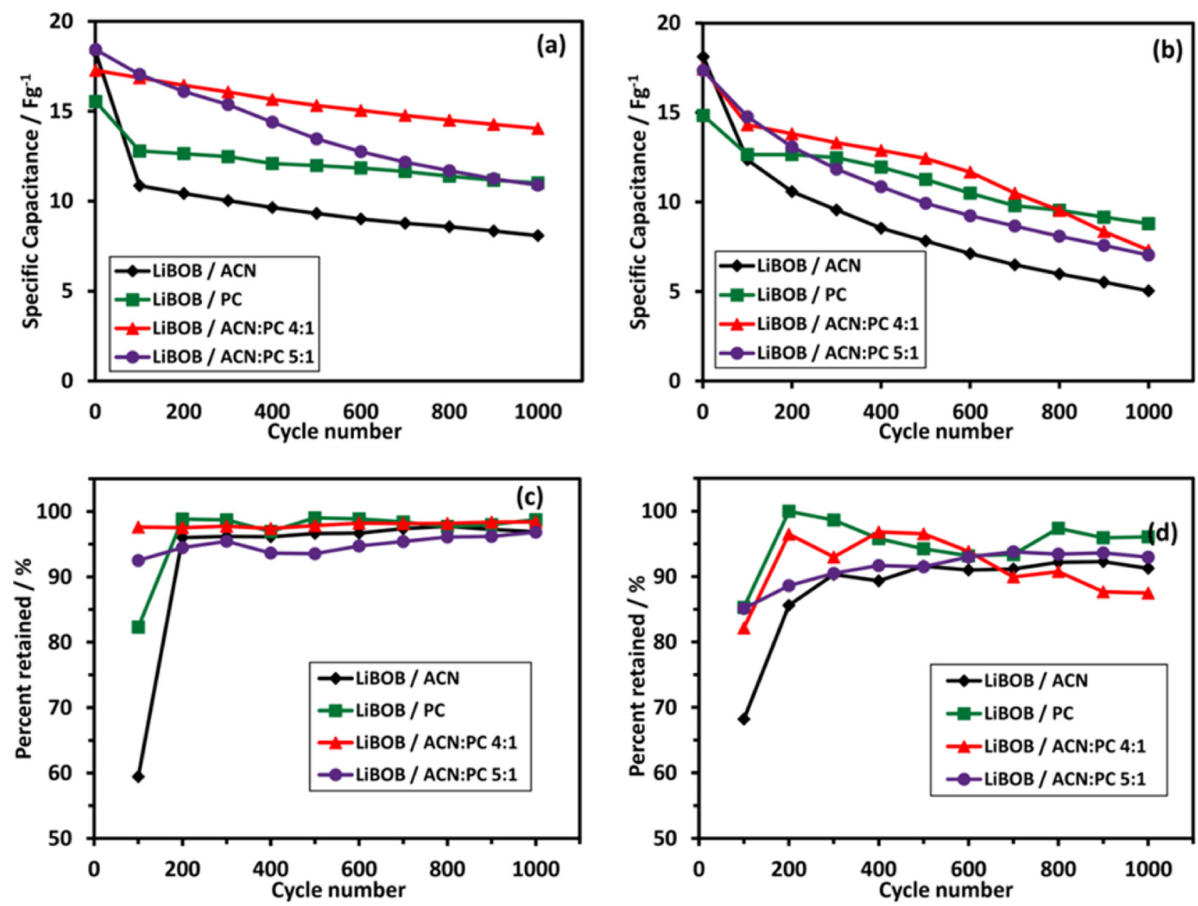

Fig. 6. Cycle test profiles of the electrolytes at (a) $2.5 \mathrm{~V}$ and (b) $2.8 \mathrm{~V}$ and their capacitance retention during cycling (c) and (d).

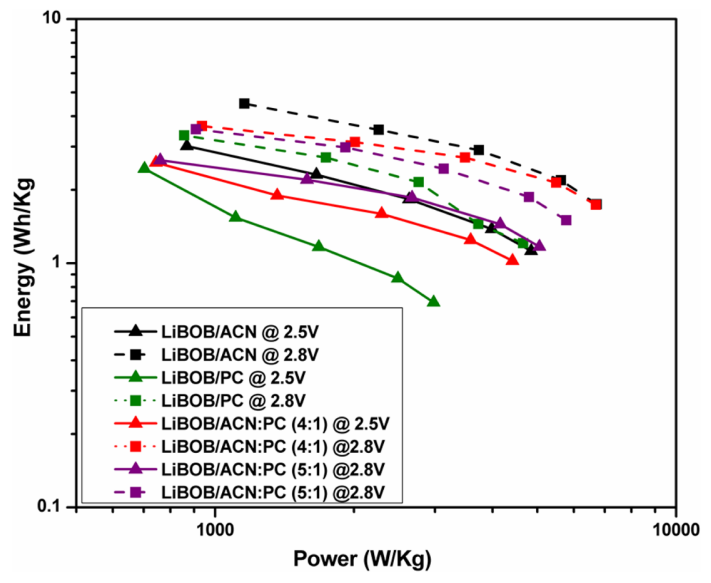

Fig. 7. Ragone plot for the electrolyte systems between 0$2.5 \mathrm{~V}$ (triangles) and $0-2.8 \mathrm{~V}$ (squares) at $80^{\circ} \mathrm{C}$.

tion successively after each cycle. Although LiBOB/ $\mathrm{PC}$ had a relatively low initial capacitance value, it could retain most of the capacitance after cycling. Both of the mixed electrolytes (LiBOB/ACN:PC) showed improved cycling behavior due to the addition of the PC component to the electrolyte. The overall result after 1000 cycles for $\mathrm{LiBOB} / \mathrm{ACN}: \mathrm{PC}$ $5: 1$ was comparable to that of the pristine $\mathrm{LiBOB} / \mathrm{PC}$ electrolyte, while $\mathrm{LiBOB} / \mathrm{ACN}: \mathrm{PC} 4: 1$ was the best in the $2.5 \mathrm{~V}$ range. Although the viscosity of the $\mathrm{PC}$ solvent was higher than that of ACN [13], PC had a much higher boiling point, which helped to improve the stability of the mixed electrolytes. In addition, the calculated specific capacitances for the mixed electrolytes and $\mathrm{LiBOB} / \mathrm{ACN}$ at $2.8 \mathrm{~V}$ were relatively lower than those obtained at $2.5 \mathrm{~V}$. Thus, an operational limit of $2.5 \mathrm{~V}$ was set for these electrolyte systems at $80^{\circ} \mathrm{C}$ for optimum performance.

The Ragone plot in Fig. 7 shows that increasing the potential range from 2.5 to $2.8 \mathrm{~V}$ resulted in a higher energy density for all respective electrolytes, which is consistent since energy is proportional to the square of the cell voltage, as shown in equation 5 . The $\mathrm{LiBOB} / \mathrm{PC}$ profiles at both voltage ranges showed a rapid decline in energy density as the power increased, which is a result of the low ionic conductivity of the solvent. This was evident, especially in the $2.8 \mathrm{~V}$ profile. $\mathrm{LiBOB} / \mathrm{ACN}$ :PC $4: 1$ showed very good stability properties in the $2.8 \mathrm{~V}$ profile. The 

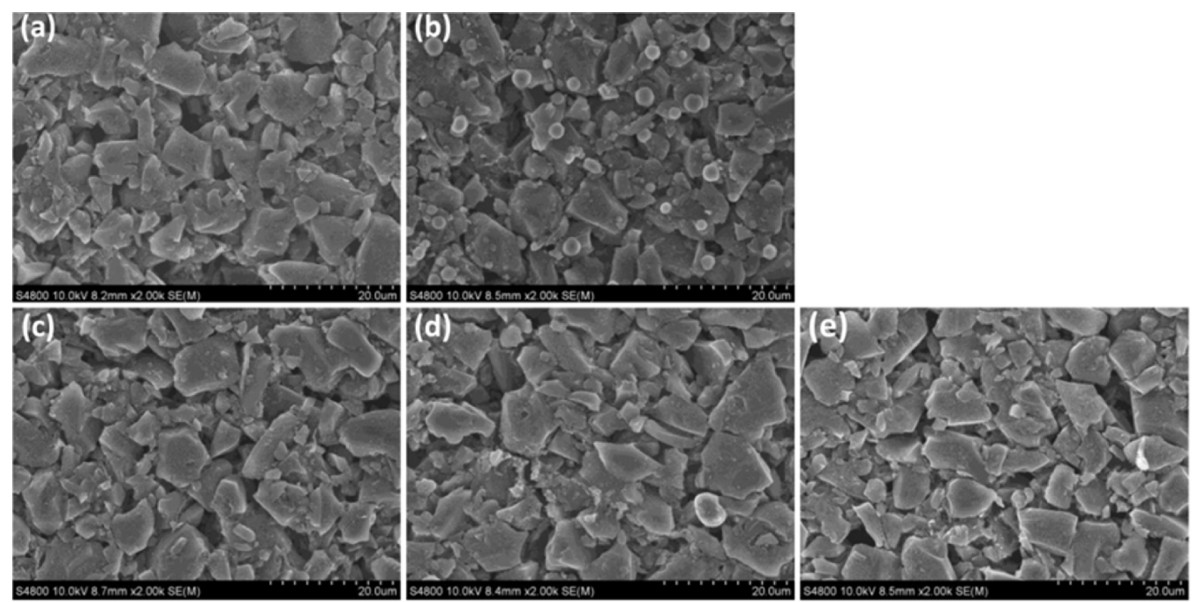

Fig. 8. SEM images of the electrode surface after cycling: (a) LiBOB/ACN, (b) LiBOB/PC, (c) LiBOB/ACN:PC 4:1, (d) $\mathrm{LiBOB} / \mathrm{ACN}: \mathrm{PC} 5: 1$, and (e) pristine electrode.

extent to which its energy values decreased as the power increased was the smallest, and thus, reaffirmed the qualities of this electrolyte blend.

\subsection{Morphological studies}

Fig. 8 shows the SEM images of the electrode surfaces taken after cycling. The SEM images of the electrodes as observed after cycling were similar in many ways to that of the pristine electrode. The LiBOB salt has been reported as a participant or contributor in solid electrolyte interphase (SEI) formation and stabilization in LIB applications [17,29].

However, there was no conclusive evidence of SEI formation due to the electrolytes on the electrode surfaces during cycling, as observed by SEM imagery. The structural integrity of the electrodes was confirmed by SEM since it showed that the images were comparable, which exhibits the good compatibility of the electrolyte systems to the activated carbon electrode.

\section{Conclusions}

The pristine $\mathrm{LiBOB} / \mathrm{ACN}$ electrolyte had a very high initial specific capacitance, which declined rapidly at an elevated temperature of $80^{\circ} \mathrm{C}$ due to the decomposition of the electrolyte solvent at that temperature. Despite this, it displayed the least initial solution resistance and good response at high scan rates due to its high ionic conductivity. On the other hand, pristine $\mathrm{LiBOB} / \mathrm{PC}$ exhibited superior cycle life resilience at $80^{\circ} \mathrm{C}$, though its delivery capacitance was relatively small because of its low ionic conductivity. The combination of the ACN and PC solvents showed improvements, as well as some tradeoffs, among the individual pristine electrolytes. Both blends had lower specific capacitances than ACN but higher than PC. LiBOB/ACN:PC 4:1 showed improved stability and cycle life properties. Overall, LiBOB in ACN and/or PC showed good characteristics for supercapacitor application with liquid organic solvents at elevated temperatures.

\section{Acknowledgment}

This research was supported by a grant(10047758) from the technology development program for strategic core materials funded by the Korean ministry of trade, industry \& energy. Also, this research was supported by basic science research program through the national research foundation of Korea(NRF) funded by the ministry of education (2017R1D1A1B04028757).

\section{References}

[1] C. Masarapu, H.F. Zeng, K.H. Hung, B. Wei, $A C S$ Nano, 2009, 3(8), 2199-2206.

[2] X. Lin, M. Salari, L.M.R. Arava, P.M. Ajayan, M.W. Grinstaff, Chem. Soc. Rev, 2016, 45(21), 5848-5887.

[3] X. Lu, M. Yu, G. Wang, Y. Tong, Y. Li, Energy Environ. Sci, 2014, 7(7), 2160-2181.

[4] K. Xu, Chem. Rev, 2004, 104(10), 4303-4418.

[5] K. Xu, Chem. Rev, 2014, 114(23), 11503-11618. 
[6] J.B. Goodenough, Y. Kim, Chem. Mater, 2010, 22(3), 587-603.

[7] B.W. Ricketts, C. Ton-That, J. Power Sources, 2000, 89(1), 64-69.

[8] H. Andreas, J. Electrochem. Soc, 2015, 162(5), A5047A5053.

[9] J. W. Kim, S.H. Choi, J.S. Kim, J. Korean Electrochem. Soc., 2017, 20(2) 34-40.

[10] E.P. Roth, C.J. Orendorff, Interface, 2012, 21(2), 45-49.

[11] M. Marcinek, et al, Solid State Ionics, 2015, 276, 107126.

[12] G. Xiong, A. Kundu, T. S. Fisher, Thermal effects in supercapacitors, 2015, Springer International Publishing.

[13] C. Zhong, Y. Deng, W. Hu, D. Sun, X. Han, J. Qiao, J. Zhang, Electrolytes for electrochemical supercapacitors, 2016, CRC Press.

[14] J. Jeong, H. Lee, H. Lee, M-H. Ryou, Y. M. Lee, J. Korean Electrochem. Soc., 2015, 18(2), 58-67.

[15] E. Frackowiak, Q. Abbas, F. Beguin, J. Energy Chem., 2013, 22(2), 226-240.

[16] K. Xu, S. Zhang, T.R. Jow, W. Xu, C.A. Angell, Electrochem. Solid-State Lett., 2002, 5(1), A26-A29.

[17] K. Xu, S.S. Zhang, U. Lee, J.L. Allen, T.R. Jow, J. Power Sources., 2005, 146(1), 79-85.

[18] W. Xu, C.A. Angell, Electrochem. Solid-State Lett.,
2001, 4(1), E1-E4

[19] S-K. You, S-G. Park, J. Korean Electrochem. Soc., 2017, 20(1), 13-17.

[20] R. Younesi, G.M. Veith, P. Johansson, K. Edstrom, T. Vegge, Energy Environ. Sci., 2015, 8(7), 1905-1922.

[21] E. Jónsson, P. Johansson, Phys. Chem., 2015, 17(5), 3697-3703.

[22] P. Johansson, J. Phys. Chem., 2006, 110(44), 207712080.

[23] V. Aravindan, J. Gnanaraj, S. Madhavi, H.K. Liu, Chem. - A Eur. J., 2011, 17(51), 14326-14346.

[24] J.W. Graydon, M. Panjehshahi, D.W. Kirk, J. Power Sources., 2014, 245, 822-829.

[25] F. Béguin, V. Presser, A. Balducci, E. Frackowiak, $A d v$. Mater.,2014, 26(14), 2219-2251.

[26] J.H. Won, M. Latifatu, M. Jang, H.S. Lee, B.-C.B.-C. Kim, L. Hamenu, J.H. Park, K.M. Kim, J.M. Ko, Synth. Met., 2015, 203, 31-36.

[27] H. Kashani, L. Chen, Y. Ito, J. Han, A. Hirata, M. Chen, Nano Energy., 2016, 19, 391-400.

[28] G. Xiong, A. Kundu, T.S. Fisher, Thermal Effects in Supercapacitors., 2015, 27-69.

[29] Z. Chen, W.Q. Lu, J. Liu, K. Amine, Electrochim. Acta., 2006, 51(16), 3322-3326. 